\title{
Influence of Factors Affecting Quality of Life on in-Hospital Cardiovascular Events of Patients with Acute Myocardial Infarction with and without ST-segment Elevation
}

Monique Tavares de Jesus, ${ }^{\circledR}$ Ingrid Maria Novais Barros de Carvalho Costa, ${ }^{1,2}{ }^{\circledR}$ Danielle Góes da Silva, ${ }^{3 \oplus}$ José Rodrigo Santos Silva, ${ }^{4 \odot}$ José Augusto Soares Barreto-Filho, ${ }^{1,5,6,7}$ Marcos Antonio Almeida-Santos, ${ }^{7,8} \circlearrowright$ Joselina Luzia Meneses Oliveira, ${ }^{1,5,6,7}$ Mirella Dornelas Batalha Moreira Buarque, ${ }^{9,10}$ Fabrício Anjos de Andrade, ${ }^{11}$ (๑) Antônio Carlos Sobral Sousa ${ }^{1,5,6,7}$ ○

Postgraduate Program in Health Sciences of the Federal University of Sergipe (UFS), ' São Cristóvão, SE - Brazil

Federal Institute of Education, Science and Technology of Sergipe, ${ }^{2}$ São Cristóvão, SE - Brazil

Nutrition Departament of the UFS, ${ }^{3}$ São Cristóvão, SE - Brazil

Statistics Departament of the UFS, ${ }^{4}$ São Cristóvão, SE-Brazil

Division of Cardiology of the University Hospital, ${ }^{5}$ Aracaju, SE - Brazil

Medicine Departament of the UFS, ${ }^{6}$ São Cristóvão, SE - Brazil

São Lucas Clínic and Hospital / Rede D'Or - São Luiz, ${ }^{7}$ Aracaju, SE - Brazil

Postgraduate Program in Health and Environment of Tiradentes University, ${ }_{1}^{8}$ Aracaju, SE - Brazil

Heart Hospital of Sergipe, ${ }^{9}$ Aracaju, SE - Brazil

Charity Foundation Surgery Hospital, ${ }^{10}$ Aracaju, SE - Brazil

Primavera Hospital," Aracaju, SE - Brazil

\section{Abstract}

Background: Acute myocardial infarction (AMI), with and without ST-segment elevation (STEMI and NSTEMI, respectively), is the principal cause of cardiovascular morbidity and mortality in Brazil and around the world. Modifiable risk factors (RF) and quality of life (QOL) may correlate with the type of AMI.

Objective: To evaluate the influence of QOL and RF on the type of AMI and in-hospital cardiovascular events in STEMI and NSTEMI patients.

Methods: This was an observational, cross-sectional study. Patients with AMI attending four referral hospitals (three private and one public) for cardiovascular disease treatment were assessed for QOL using the Brazilian version of the 36-item short form survey. A $p<0.05$ was considered statistically significant.

Results: We evaluated 480 volunteers; $51 \%$ were treated in one of the private hospitals. In total, $55.6 \%$ presented with STEMI, and $44.4 \%$ with NSTEMI. Patients from the public hospital were 8.56 times more likely to have STEMI compared to those from the private hospitals. There was a higher prevalence of smokers in STEMI $(\mathrm{p}<0.028)$ patients. QOL was not associated with the type of AMI. A negative patient perception of the physical health and pain domains was observed. Although a significant difference between the physical and the mental health domains was not observed, individual domains were correlated with some in-hospital outcomes.

Conclusion: There was a higher prevalence of smokers among individuals with STEMI. Domains of QOL showed a statistically significant relationship with the occurrence of in-hospital cardiovascular events, with no difference between the types of AMI.

Keywords: Cardiovascular Diseases/epidemiology; Coronary Acute, Syndrome; Myocardial Infarction; Myocardial Infarction; Medication Adherence ; Risk Factors. 


\section{Introduction}

The global scenario reveals an increase in the incidence of cardiovascular diseases. ${ }^{1}$ According to a report by the Pan American Health Organization (PAHO) published in 2017, 17.7 million people died from cardiovascular disease in 2015 , representing $31 \%$ of all deaths globally. It directly affects health-related costs, and causes reduction in job productivity and quality of life (QOL). ${ }^{2,3}$

Acute coronary syndromes (ACS), including unstable angina (UA) and acute myocardial infarction (AMI) with and without ST-segment elevation (STEMI and NSTEMI, respectively) are among the main cardiovascular diseases. ${ }^{4}$ AMI is one of the leading causes of death and physical disabilities, and modifiable risk factors (RF) and QOL may correlate with the development of this disease. ${ }^{5-7}$

According to the PAHO report, most cardiovascular diseases can be prevented by addressing behavioral $\mathrm{RF}$, such as tobacco use, unhealthy diet, obesity, lack of physical activity, and use of alcohol, by implementing strategies for the general population. ${ }^{2}$ Additionally, control of RF and adherence to healthy habits can be associated with better QOL. ${ }^{8}$

QOL is related to the individual's perception of their own life, in connection with their goals and within the value system incorporated in decision-making. ${ }^{9}$ It depends on individual's economic status, physical and mental health, social protection, political stability, and the environment. ${ }^{10}$

The measurement of QOL provides valuable information about the individual and helps clinicians to choose the best forms of treatment and rehabilitation. Despite the relationship between RF and the lifestyle of individuals with cardiovascular disease, recommendations to investigate parameters of QOL for estimation of cardiovascular events (CVEs), are not well established, and require further research. Therefore, the present study aimed to assess whether patient QOL affects the type of AMI and in-hospital outcomes.

\section{Methods}

\section{Study design}

This was a cross-sectional observational study, carried out from October 2013 to September 2015. This study is part of the research entitled "Adherence to drug treatment and lifestyle changes in patients with acute coronary syndrome" conducted in four renowned hospitals for cardiac treatments (three private and one public) in Aracaju, Sergipe, Brazil. ${ }^{11}$

\section{Subjects}

Patients who presented with STEMI or NSTEMI were recruited by convenience sampling. We included patients of both genders, aged 18 years or older, diagnosed with AMI, and excluded patients with cardiogenic shock, unstable angina (UA), or Alzheimer's disease.

\section{Variables analyzed}

The following variables, collected from medical records were analyzed: educational attainment, marital status, clinical presentation (type of infarction), comorbidities - dyslipidemia, systemic arterial hypertension (SAH), smoking, diabetes mellitus (DM), and family history of coronary artery disease (CAD) - and in-hospital events.

We performed anthropometric measurements weight, height, waist circumference, and body mass index (BMI). We also analyzed physical activity records using the International Physical Activity Questionnaire (IPAQ, short version), ${ }^{12,13}$ and QOL using the Brazilian version of the Medical Outcomes Study Questionnaire 36-Item Short-Form Health Survey (SF-36). ${ }^{14,15}$

\section{Anthropometric measurements}

Body weight, height, and $\mathrm{BMI}^{16}$ of patients were determined. For body weight measurement, patients were dressed in light clothing, barefoot, standing on the platform of a digital scale (Filizola, $150 \mathrm{Kg}$ ) to the nearest $0.1 \mathrm{Kg}$. Height was measured to the nearest $0.1 \mathrm{~m}$ using a stadiometer (SECA).

\section{Physical activity}

We used the IPAQ - short version to assess physical activity. Habitual physical activity levels were classified based on the consensus proposed by the Physical Fitness Laboratory of São Caetano do Sul, which is the coordinating center of IPAQ in Brazil. Patients were then classified into very active, active, irregularly active, and sedentary. ${ }^{12,13}$ 


\section{Quality of life}

QOL was measured using the validated Portuguese language version ${ }^{14}$ of the SF-36 questionnaire. ${ }^{15}$

The SF-36 consists of 36 questions that address eight domains (or dimensions) of two major components: the physical component that involves functional capacity (10 items), pain (two items), general health status (five items), and physical performance (four items), and the mental component that covers mental health (five items), emotional (three items), social (two items), and vitality (four items). There is also one question aimed to compare current health perceived by the patient with that of a year ago. ${ }^{14,15}$

\section{Data analysis}

We analyzed the data using the software $\mathrm{R}$, version 3.5.1. Univariate descriptive analysis was performed by calculating the frequencies (absolute and relative) for the categorical variables, and mean and standard deviation for the continuous variables. Continuous variables that were not normally distributed were described as median and interquartile range.

Continuous variables with normal and without normal distribution were compared using the unpaired Student's t-test and the Mann-Whitney, respectively. Distribution normality was assessed using the Shapiro-Wilk test. For categorical variables, the chi-square test or the Fisher's exact test, with $95 \%$ confidence interval, was used as appropriate. The odds ratio (OR) was also calculated. Significance level was set at $0.05(\mathrm{p}<0.05)$.

\section{Ethical aspects}

The study was approved by the Research Ethics Committee of the Federal University of Sergipe - CEP/ UFS on 06/07/2013 under $n^{\circ}$ 302.544. All procedures were performed following the 2013 update of the Declaration of Helsinki. Informed consent was obtained from all the participants included in the study.

\section{Results}

\section{Characteristics of the subjects}

A total of 480 patients were included. Out of these patients, 267 (56\%) had STEMI, and 213 (44\%) had NSTEMI. Among them, 235 (49\%) were treated in the public hospital, and $245(51 \%)$ in private ones. The study sample was predominantly elderly and male. Most of them had complete elementary school and were married or lived with a partner. Regarding RF, most patients were overweight and had a sedentary lifestyle, were non-smokers, had SAH, dyslipidemia, and family history of CAD (Table 1).

Considering the type of hospital, 189 patients who were treated in the public hospital were diagnosed with STEMI, compared with 78 patients with STEMI who were treated in private hospitals. Therefore, in the public health system, $80 \%$ of the patients with AMI were diagnosed with STEMI, compared to $32 \%$ in the private hospitals $(p<0.001)$, indicating a relationship between the type of AMI and the type of hospital. People treated in the public hospital were 8.56 times more likely to have STEMI compared to those treated in the private hospitals (Table 2).

In addition, 183 (60\%) of men had STEMI, compared to $84(48 \%)$ of women. Men had a 1.62 times greater chance of having STEMI compared to women $(\mathrm{p}=0.014)$. Low educational attainment and age group (between 18 and 49 years) also showed a significant relationship with the severity of infarction (Table 2).

Smoking, DM, SAH, dyslipidemia, obesity/overweight (BMI), and physical inactivity showed a significant relationship with the development STEMI. In the univariate analysis, these variables did not show any statistically significant differences related to the type of infarction (Table 2).

\section{QOL, AMI type, and in-hospital outcome}

Considering that the SF-36 score ranges from 0 to 100 (with 0 being the worst state and 100 the best state), the mean scores for all domains ranged from 41 to 69. Only the physical aspects of the domains and pain had a mean value below 50. Social and mental health domains had the highest averages (Table 3) ${ }^{16}$. Comparisons of mean SF-36 scores between STEMI and NSTEMI showed no statistically significant differences (Table 4 ). ${ }^{17}$

Table $5^{18}$ shows the mean F-36 scores of AMI patients with and without in-hospital events. Functional capacity showed a statistically significant relationship in the univariate analysis with cardiovascular death $(\mathrm{p}<0.024)$. Likewise, a statistically significant relationship between pain and acute and chronic renal failure $(\mathrm{p}<0.041)$, and between cardiovascular death and physical performance $(p<0.040)$ was also found. 
Table 1 - General characteristics of patients $(n=480)$ with acute myocardial infarction, Aracaju, Sergipe, Brazil, 2019

\begin{tabular}{|c|c|c|}
\hline Variables & Category & Frequency $\left(n^{\circ}\right)(\%)$ \\
\hline \multirow{2}{*}{ ACS type } & STEMI & $267(56)$ \\
\hline & NSTEMI & $213(44)$ \\
\hline \multirow{2}{*}{ Health service } & Public & $236(49)$ \\
\hline & Private & $244(51)$ \\
\hline \multirow{2}{*}{ Sex } & Masculine & $305(64)$ \\
\hline & Feminine & $175(36)$ \\
\hline \multirow{3}{*}{ Color } & White & $164(36)$ \\
\hline & Black & $64(14)$ \\
\hline & Brown & $230(50)$ \\
\hline \multirow{3}{*}{ Educational attainment } & Elementary School & $266(55)$ \\
\hline & High School & $142(30)$ \\
\hline & Higher Education & $72(15)$ \\
\hline \multirow{2}{*}{ Weight excess } & Yes & 317 (67) \\
\hline & No & $159(33)$ \\
\hline \multirow{3}{*}{ Tobacco use } & Yes & $92(19)$ \\
\hline & Ex-smoker & $170(35)$ \\
\hline & No & $218(45)$ \\
\hline \multirow{2}{*}{ DM } & Yes & $169(35)$ \\
\hline & No & $311(65)$ \\
\hline \multirow{2}{*}{ SAH } & Yes & $103(21)$ \\
\hline & No & $377(79)$ \\
\hline \multirow{2}{*}{ Dyslipidemia } & Yes & $263(55)$ \\
\hline & No & $217(45)$ \\
\hline \multirow{2}{*}{ History of CAD } & Yes & $276(58)$ \\
\hline & No & $204(43)$ \\
\hline \multirow{2}{*}{ IPAQ } & Sedentary & $254(53)$ \\
\hline & Active & $226(47)$ \\
\hline \multirow{5}{*}{ Age group } & from 18 to 49 & $63(13)$ \\
\hline & from 50 to 59 & $117(24)$ \\
\hline & from 60 to 69 & $158(33)$ \\
\hline & from 70 to 79 & $93(19)$ \\
\hline & 80 or over & $49(10)$ \\
\hline \multirow{3}{*}{ Marital status } & Married/Stable union & $315(66)$ \\
\hline & Divorced/Widow(er)/ & $101(21)$ \\
\hline & Single & $63(13)$ \\
\hline
\end{tabular}


Table 2 - Relationship between types of acute myocardial infarction with qualitative variables, Aracaju, Sergipe, Brazil, 2019

\begin{tabular}{|c|c|c|c|c|}
\hline \multirow{2}{*}{ Variable / Category } & \multicolumn{2}{|c|}{ AMI } & \multirow{2}{*}{ OR (CI 95\%) } & \multirow{2}{*}{ p-value* } \\
\hline & STEMI (\%) & NSTEMI (\%) & & \\
\hline \multicolumn{5}{|l|}{ Health Service } \\
\hline Public & $189(80)$ & $47(20)$ & $8.56(5.64-12.99)$ & $<0.001$ \\
\hline Private & $78(32)$ & $166(68)$ & 1.00 & \\
\hline \multicolumn{5}{|l|}{ Sex } \\
\hline Masculine & $183(60)$ & $122(40)$ & $1.62(1.12-2.36)$ & 0.014 \\
\hline Feminine & $84(48)$ & $91(52)$ & 1.00 & \\
\hline \multicolumn{5}{|l|}{ Race (skin color) } \\
\hline White & $79(48)$ & $85(52)$ & $0.68(0.45-1.01)$ & 0.071 \\
\hline Black & $40(63)$ & $24(38)$ & $1.22(0.69-2.15)$ & \\
\hline Brown & $133(58)$ & $97(42)$ & 1.00 & \\
\hline \multicolumn{5}{|l|}{ Education } \\
\hline Elementary school & $174(65)$ & $92(35)$ & $2.97(1.74-5.08)$ & $<0.001$ \\
\hline High school & $65(46)$ & $77(54)$ & $1.33(0.74-2.36)$ & \\
\hline Higher education & $28(39)$ & $44(61)$ & 1.00 & \\
\hline \multicolumn{5}{|l|}{ Overweight/Obesity } \\
\hline Yes & $171(54)$ & $146(46)$ & $0.85(0.58-1.25)$ & 0.476 \\
\hline No & $92(58)$ & $67(42)$ & 1.00 & \\
\hline \multicolumn{5}{|l|}{ Tobacco use } \\
\hline Yes & $60(65)$ & $32(35)$ & $1.91(1.15-3.16)$ & 0.028 \\
\hline Ex-smoker & $99(58)$ & $71(42)$ & $1.42(0.95-2.13)$ & \\
\hline No & $108(50)$ & $110(50)$ & 1.00 & \\
\hline \multicolumn{5}{|l|}{ DM } \\
\hline Yes & $90(53)$ & $79(47)$ & $0.86(0.59-1.26)$ & 0.500 \\
\hline No & $177(57)$ & $134(43)$ & 1.00 & \\
\hline \multicolumn{5}{|l|}{ Hypertension } \\
\hline Yes & $56(54)$ & $47(46)$ & $0.94(0.61-1.45)$ & 0.859 \\
\hline No & $211(56)$ & $166(44)$ & 1.00 & \\
\hline \multicolumn{5}{|l|}{ Dyslipidemia } \\
\hline Yes & $136(52)$ & $127(48)$ & $0.70(0.49-1.01)$ & 0.071 \\
\hline No & $131(60)$ & $86(40)$ & 1.00 & \\
\hline \multicolumn{5}{|l|}{ History of CAD } \\
\hline Yes & $151(55)$ & $125(45)$ & $0.92(0.64-1.32)$ & 0.707 \\
\hline No & $116(57)$ & $88(43)$ & 1.00 & \\
\hline \multicolumn{5}{|l|}{ IPAQ } \\
\hline Sedentary & $139(55)$ & $115(45)$ & $0.93(0.65-1.33)$ & 0.742 \\
\hline
\end{tabular}




\begin{tabular}{lccc}
\hline Active & $128(57)$ & $98(43)$ & 1.00 \\
\hline Age group & & & $3.51(1.60-7.68)$ \\
\hline from18 to 49 & $41(65)$ & $22(35)$ & $2.91(1.45-5.82)$ \\
\hline from 50 to 59 & $71(61)$ & $46(40)$ & $2.31(1.18-4.49)$ \\
\hline from 60 to 69 & $87(55)$ & $71(45)$ & $2.29(1.12-4.68)$ \\
\hline from 70 to 79 & $51(55)$ & $42(45)$ & 1.00 \\
\hline 80 or over & $17(35)$ & $32(65)$ & $0.62(0.35-1.10)$ \\
\hline Marital status & $175(56)$ & $140(44)$ & $0.47(0.25-0.91)$ \\
\hline Married/Stable union & $49(49)$ & $52(51)$ & 1.00 \\
\hline $\begin{array}{l}\text { Divorced/Widow(er)/ } \\
\text { Single }\end{array}$ & $42(67)$ & 21 (33) & 0.075 \\
\hline $\begin{array}{l}* \\
\text { NSTi-square or Fisher's exact test. OR: Odds Ratio, AMI: Acute Myocardial Infarction; STEMI: Acute Myocardial Infarction with ST-segment elevation; } \\
\text { Physical Activity Questionnaire. }\end{array}$ & & \\
\hline
\end{tabular}

Table 3 - Summary of quantitative variables of the SF-36 questionnaire of acute myocardial infarction patients $(n=480)^{16}$

\begin{tabular}{lccc}
\hline Domains & Average & Median & Standard deviation \\
\hline FUNCTIONAL CAPACITY & 54 & 55 & 32 \\
\hline PHYSICAL & 41 & 25 & 42 \\
\hline PAIN & 48 & 41 & 30 \\
\hline HEALTH & 58 & 60 & 22 \\
\hline VITALITY & 60 & 60 & 24 \\
\hline SOCIAL & 68 & 75 & 29 \\
\hline EMOTIONAL & 60 & 100 & 44 \\
\hline MENTAL & 69 & 72 & 22
\end{tabular}

Unexpectedly, we did not observe a statistically significant difference between the mean scores of physical and mental health regarding the CVEs that occurred during hospitalization. We observed an association between emotional domain and congestive heart failure (CHF) $(\mathrm{p}<0.004)$. Vitality was significantly related to the onset of CHF ( $\mathrm{p}<0.045)$, cardiovascular death ( $\mathrm{p}$ $<0.012)$, and reinfarction $(\mathrm{p}<0.007)$. The social aspect also showed a statistically significant relationship with CVEs, including angioplasty $(\mathrm{p}<0.049)$, myocardial revascularization (MR) $(\mathrm{p}<0.033)$, cardiovascular death $(\mathrm{p}<0.047)$, and reinfarction $(\mathrm{p}<0.010)$.

\section{Discussion}

The study sample was predominantly elderly and male, and a family history of CAD was found in $58 \%$ of the patients. These three factors (age, sex, and history of CAD) are classified as non-modifiable RF. Among the modifiable RF, the most prevalent were obesity, hypertension, dyslipidemia, and physical inactivity; most patients were non-smokers or ex-smokers.

In a multicenter study carried out in Brazil, most patients were also male, with an average age varying between 61 and 65 years. ${ }^{19}$ International studies have also reported 
higher incidences of AMI in male elderly populations. ${ }^{20,}$ ${ }^{21}$ This may be related to the high life expectancy and men's health gap, which causes an increased prevalence of these chronic-degenerative diseases.

Regarding the type of infarction, there was a higher prevalence of STEMI (56\%) compared to NSTEMI (44\%). Marino et al.,22 described the profile of patients with ACS and found a higher prevalence of STEMI patients $(\mathrm{n}=214)$ compared with NSTEMI patients $(\mathrm{n}=73) .{ }^{22}$ The literature shows that the incidence of STEMI and NSTEMI varies across the world, and that, in European countries, the incidence of NSTEMI has been increasing. ${ }^{23,24}$

Regarding the type of hospital (public vs. private), the number of patients attending public (49.2\%) and private hospitals (50.8\%) was similar. Regarding the type of AMI, the number of STEMI cases was higher in the public hospital than in private hospitals. This may be explained by the fact that the public hospital where the study was conducted is a referral center for cardiac surgery in the Brazilian Unified Health System (SUS). In the patient selection process for surgery, higher priority is given to patients with STEMI.

Regarding the relationship between the type of AMI and RF, there was a significant correlation between STEMI and smoking. The nicotine present in tobacco is the most addictive psychoactive drug, and responsible for raising heart rate and blood pressure, in addition to promoting thrombogenicity. Approximately 21\% of deaths are associated with tobacco. Smoking also interferes with individuals' QOL. ${ }^{25,26}$

With respect to perception of health-related QOL by all the respondents, the mean scores for the domains of physical component and pain were low when compared with the dimensions of vitality, and social, emotional, and mental health. Studies that evaluated QOL during hospitalization observed a negative perception of QOL in both physical and pain domains, as well as of sleep and emotional reactions. The latter two were related to the type of AMI and the process of hospitalization. 27,28 Angina, together with feelings triggered by hospitalization, can influence pain and physical aspects.

In the last decades, research investigating the QOL of cardiac patients has reported a decline in their physical capacity due to dyspnea and fatigue. ${ }^{29,30}$ The present study corroborates these findings and reinforces that these individuals require proper management not only of pain but also of the decline in physical capacity.
Contrary to expectations, we found no significant difference in QOL between the two types of AMI. Another similar study ${ }^{23}$ also found no significant difference between the AMI types, corroborating our results. This study also observed a reduction in patient QOL for all domains, except for the general health domain, following in-hospital CVEs. ${ }^{23}$

Mollon and Bhattacharjee, ${ }^{31}$ in a case-control study, identified that individuals who suffered AMI had lower QOL in the domains of general, physical, and mental health compared to individuals without AMI. In the domains of sleep, emotional support, and life satisfaction, there were no differences between AMI survivors and the control group. ${ }^{31}$

When analyzing the relationship between QOL and in-hospital outcomes of our patients, we identified that functional capacity, physical, social, and vitality domains were associated with cardiovascular death. New episodes of AMI were related to the vitality and social domains, and $\mathrm{CHF}$ was associated with the emotional and vitality domains. Regarding pain, higher scores were reported by the patients with acute and chronic renal failure.

Furthermore, in the present study, the occurrence of sepsis was related to functional capacity, and angioplasty and myocardial revascularization (MR) were associated with the social domain. Contrary to our expectations mean scores for the physical and the mental health dimensions were not different when the in-hospital events were considered.

Therefore, the social domain was related to a higher risk of in-hospital events. In a similar study, which evaluated the quality of life after MR surgery, we observed that the domain social relationships had the second highest score. ${ }^{31}$ According to Souza et al., ${ }^{32}$ social support can act as a protective factor, by relieving stress during crises and facilitating the recovery from the disease. ${ }^{32}$

A major scientific challenge is the improvement in the evaluation of mortality predictors as well as the establishment of appropriate treatment. However, it is common sense to combine the established RF and the factors known to interfere with patient's QOL for the creation of educational programs. One of the relevant achievements of the present study was to identify the differences in the QOL scores according to in-hospital events. These findings can serve as a basis for new scientific projects. Moreover, they prove that psychosocial factors are involved in the development and recovery from the disease. 


\begin{tabular}{|c|c|c|c|c|c|c|c|}
\hline \multirow{2}{*}{ Domain } & \multicolumn{3}{|c|}{ STEMI } & \multicolumn{3}{|c|}{ NSTEMI } & \multirow{2}{*}{ p-value* } \\
\hline & Median & P25 & P75 & Median & P25 & P75 & \\
\hline $\begin{array}{l}\text { FUNCTIONAL } \\
\text { CAPATICY }\end{array}$ & 55 & 30 & 80 & 55 & 25 & 85 & 0.894 \\
\hline PHYSICAL & 25 & 00 & 100 & 25 & 00 & 75 & 0.091 \\
\hline PAIN & 41 & 20 & 72 & 41 & 20 & 62 & 0.688 \\
\hline HEALTH & 62 & 42 & 77 & 57 & 42 & 72 & 0.544 \\
\hline VITALITY & 65 & 45 & 83 & 60 & 40 & 75 & 0.065 \\
\hline SOCIAL & 75 & 50 & 100 & 63 & 50 & 100 & 0.073 \\
\hline EMOTIONAL & 100 & 00 & 100 & 100 & 00 & 100 & 0.564 \\
\hline MENTAL & 72 & 56 & 88 & 72 & 52 & 84 & 0.285 \\
\hline
\end{tabular}

Some limitations should be considered when interpreting the results. The QOL questionnaire was administered retrospectively, and hence participants' responses relied on their memories. Additionally, since this is a generic tool, it did not focus on characteristics of AMI, and did not include diet as a risk factor.

\section{Conclusion}

In the present investigation, we observed that, compared with NSTEMI patients, a higher prevalence of smokers was observed among STEMI patients. The other RF evaluated were associated with both types of AMI equally.

We observed a negative perception in the domains of physical aspects and pain of QOL in STEMI and NSTEMI patients, with no difference in QOL between these two groups. Regarding the association of QOL with in-hospital CVEs, a significant association was found of physical and mental health with the occurrence of events.

\section{Author contributions}

Conception and design of the research: Jesus MT, Costa IMNBC, Silva DG, Silva JRS, Buarque MDBM, Sousa ACS. Acquisition of data: Jesus MT, Costa IMNBC, Buarque MDBM, Andrade FA, Sousa ACS. Analysis and interpretation of the data: Jesus MT, Costa IMNBC, Silva DG, Silva JRS, Barreto Filho JAS, Almeida-Santos MA,
Oliveira JLM, Sousa ACS. Statistical analysis: Silva JRS. Writing of the manuscript: Jesus MT, Silva DG, AlmeidaSantos MA, Oliveira JLM, Sousa ACS. Critical revision of the manuscript for intellectual content: Jesus MT, Silva DG, Almeida-Santos MA, Oliveira JLM, Sousa ACS.

\section{Potential Conflict of Interest}

No potential conflict of interest relevant to this article was reported.

\section{Sources of Funding}

There were no external funding sources for this study.

\section{Study Association}

This article is part of the thesis of master submitted by Monique Tavares de Jesus, from Universidade Federal de Sergipe.

\section{Ethics approval and consent to participate}

This study was approved by the Ethics Committee of the Universidade de Sergipe under the protocol number 302.544. All the procedures in this study were in accordance with the 1975 Helsinki Declaration, updated in 2013. Informed consent was obtained from all participants included in the study. 


\section{Table 5 - Distribution of SF-36 domain scores according to the occurrence of in-hospital events in acute myocardial infarction patients ${ }^{18}$}

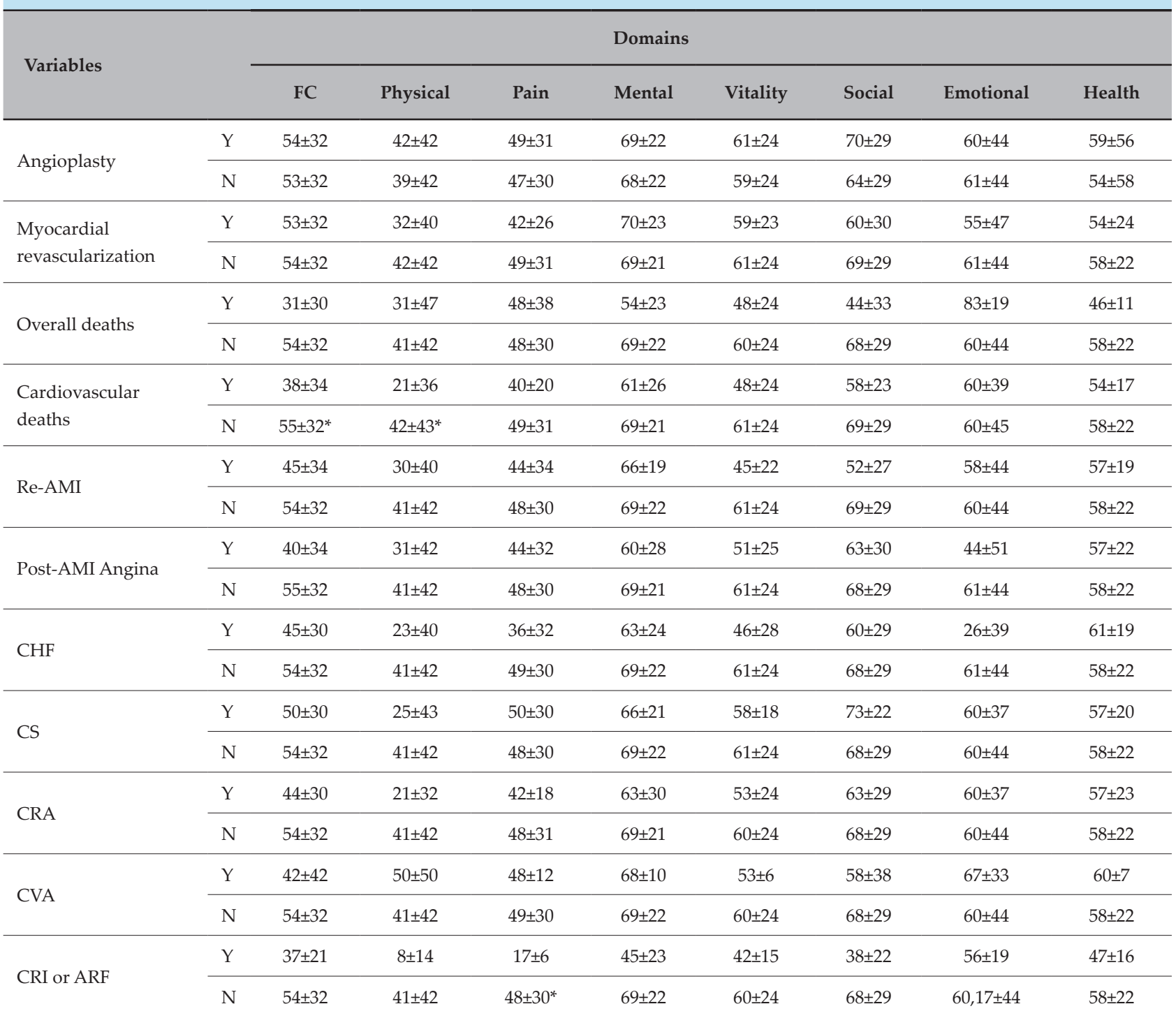

FC: Functional Capacity MR: Myocardial Revascularization; AMI: Acute Myocardial Infarction; CS: Cardiogenic Shock; CRA: Cardiorespiratory Arrest; CHF: Congestive Heart Failure; CVA: Cerebrovascular Accident; CRI: Chronic Renal Insufficiency; ARF: Acute Renal Failure; Y: yes; N: no. *: $p$ value $<0,05$.

\section{References}

1. Huguenin FM, Pinheiro RS, Almeida RM, Infantos, AF. Caracterização dos padrões de variação dos cuidados de saúde a partir dos gastos com internações por infarto agudo do miocárdio no Sistema Único de Saúde. Rev. Bras. Epidemiol. 2016;19(2):229-42.

2. Organização Pan-Americana de Saúde(OPAS). Doenças Cardiovasculares, 2017. [Cited in 2019 Ju 2]. Available from: https://www.paho.org/bra/

3. Stevens B, Pezzullo L, Verdian L, Tomlinson J, George A, Bacal F. Os Custos das Doenças Cardíacas no Brasil. Arq Bras Cardiol. 2018;111(1):29-36.

4. Silva RB, Castro CM, Iser BP, Castilho LG. Perfil dos pacientes com síndromes coronarianas agudas em um hospital da Região Sul do Brasil. Rev Soc Bras Clin Med. 2016;14(1):33-7.
5. World Health Organization (WHO). World report on ageing and health. Geneva; 2015.

6. Goswami DS, Manohar TP. Cardiometabolic Risk Factors in Acute Coronary Syndrome with Special Reference to Non-HDL Cholesterol. J. Assoc. Physicians India. 2016;64(10):30-6.

7. Mannsverk J, Wilsgaard T, Mathiesen EB, Lochen ML, Rasmussen K, Thelle DS, et al. Trends in modifiable risk factors are associated with declining incidence of hospitalized and nonhospitalized acute coronary heart disease in a population. Circulation. 2016;5(133):74-81.

8. Cunha EF, Silva AM, Saad KR, Melo TA, Martinez BP, Carvalho VO, et al. Avaliação do estilo de vida de pacientes com infarto agudo do miocárdio admitidos em uma unidade coronariana. Rev Soc Bras Clin Med. 2016;14(1):18-21. 
9. Higginson IJ, Carr AJ. Using quality of life measures in the clinical setting. BMJ. 2001; 322 (7297):1297-300.

10. Dzubur A, Mekic M, Pesto S, Nabil N. Echocardiographic parameters as life quality predictors in patients after myocardial infarction treated with different methods. med arch. 2016;70(6):419-24.

11. Costa IM, Silva DG, Barreto-Filho JA, Oliveira JL, Silva JR, Buraque MD, et al. Diet quality of patients with acute coronary syndrome receiving public and private health care. Nutrition. 2019 Mar;59:131-7.

12. IPAQ Research Committee. Guidelines for the data processing and analysis of the International Physical Activity Questionnaire. No. 2005. [Cited in 2019 Ju 2]. Available from: http://www.ipaq.ki.se/scoring.pdf.

13. Matsudo S, Araújo T, Matsudo V, Andrade D, Andrade E, Oliveira L, et al. Questionário Internacional de Atividade Física (IPAQ): estudo de validade e reprodutibilidade no Brasil. Rev Bras de Ativ Fís Saúde. 2001;6(2):5-12.

14. Ciconelli RM, Ferraz MB, Santos W, Meinão I, Quaresma MR. Tradução para a língua portuguesa e validação do questionário genérico de avaliação da qualidade de vida SF-36 (Brasil SF-36). Rev Bras Reumatol. 1999;39(3):143-50.

15. Ware JE, Sherbourne CD. The Mos 36-item short-form health survey (SF36). I. Conceptual frame work and item selection. Med Care. 1992;30(6):473-83.

16. World Health Organization.(WHO) Obesity: preventing and managing the global epidemic. Report of a WHO consultation on obesity. Geneva; 1998.

17. World Health Organization. Physical status: the use and interpretation of anthropometry. Geneva; 1995.

18. Lipschitz DA. Screening for nutritional status in the elderly. Primary Care. 1994;21(1):55-67.

19. Wang R, Neuenschwander FC, Filho AL, Moreira CM, dos Santos ES, et al. Uso de Intervenções Baseadas em Evidências na Síndrome Coronária Aguda - Subanálise do Registro ACCEPT. Arq Bras Cardiol. 2014;102(4):319-326.

20. Krzysztofik MJ, Sokolski M, Kosowski M, Zimoch W, Lis A, Klepuszewski et al. Acute heart failure in patients admitted to the emergency department with acute myocardial infarction. Kardiologia Polska. 2017;75(4):306-15.

21. Ağaç MT, Ağaç S, Korkmaz L, Erkan H, Turan T, Bektaş Het al. A simple angiographic index to predict adverse clinical outcome associated with acute myocardial infarction. Türk Kardiyol Dern Arş - Arch Turk Soc Cardiol. 2014; 42(4):321-9.
22. Marino BC, Marcolino MS, Júnior RS, França AL, Passos PF, Lemos TR, et al. Perfil epidemiológico e indicadores de qualidade em pacientes com síndrome coronariana aguda na região norte de minas gerais - Projeto Minas Telecardio 2. Arq Bras Cardiol. 2016;107(2):106-15.

23. Mahesh PK, Gunathunga MW, Jayasinghe S, Arnold SM, Haniffa R, Silva AP. Pre-event quality of life and its influence on the post-event quality of life among patients with ST elevation and non-ST elevation myocardial infarctions of a premier province of Sri Lanka. Health and Quality of Life Outcomes. 2017;15(54):1-10.

24. Steg PG, James SK, Atar D, Badano LP, Blömstrom-Lundqvist C, Borger MA, et al. Guidelines for the management of acute myocardial infarction in patients presenting with ST-segment elevation: The task force on the management of ST-segment elevation acute myocardial infarction of the European Society of Cardiology (ESC). Eur Heart J. 2012;33(20):2569-619.

25. Pinto MT, Pichon-Riviere A, Bardach A. Estimativa da carga do tabagismo no Brasil: mortalidade, morbidade e custos. Cad. Saúde Pública. 2015;31(6):1283-97.

26. Simão AF, Précoma DB, Andrade JP, Correa FH, Saraiva JF, Oliveira GM, et al. Sociedade Brasileira de Cardiologia. I Diretriz Brasileira de Prevenção Cardiovascular. Arq Bras Cardiol. 2013;101(2):1-63.

27. Santos JR, Reis SC, Reis MC, Soares AB, Jucá AL. Qualidade de vida de pacientes hospitalizados com doenças cardiovasculares: possibilidades de intervenção da terapia ocupacional. Rev Interinst Bras Ter Ocup. 2017;1(5):620-33.

28. Dessotte CA, Dantas RA, Schmidt A, Rossi LA. Qualidade de vida relacionada à saúde de sujeitos internados, decorrentes da primeira síndrome coronariana aguda. Rev. Latino-am. Enfermagem. 2011; 19(5):2-8.

29. The WHOQOL Group. The World Health Organization Quality of Life Assessment (WHOQOL): Position paper from the World Health Organization. Soc. Sci. Med. Oxford. 1995; 41(10):1403-9.

30. Mollon L, Bhattacharjee S. Health related quality of life among myocardial infarction survivors in the United States: a propensity score matched Analysis. Health and Quality of Life Outcomes. 2017; 15(235):1-10.

31. Araújo HV, Figueiredo TR, Costa CR, Silveira MM, Belo RM, Bezerra SM Quality of life of patients who undergone myocardial revascularization surgery. Rev Bras Enferm. 2017;70(2):257-64.

32. Souza AR, Albuquerque LF, Silva FA, Machado RC. Fatores associados a um impacto na qualidade de vida pós revascularização miocárdica. Rev Rene. 2018; 19(3459):1-10. 